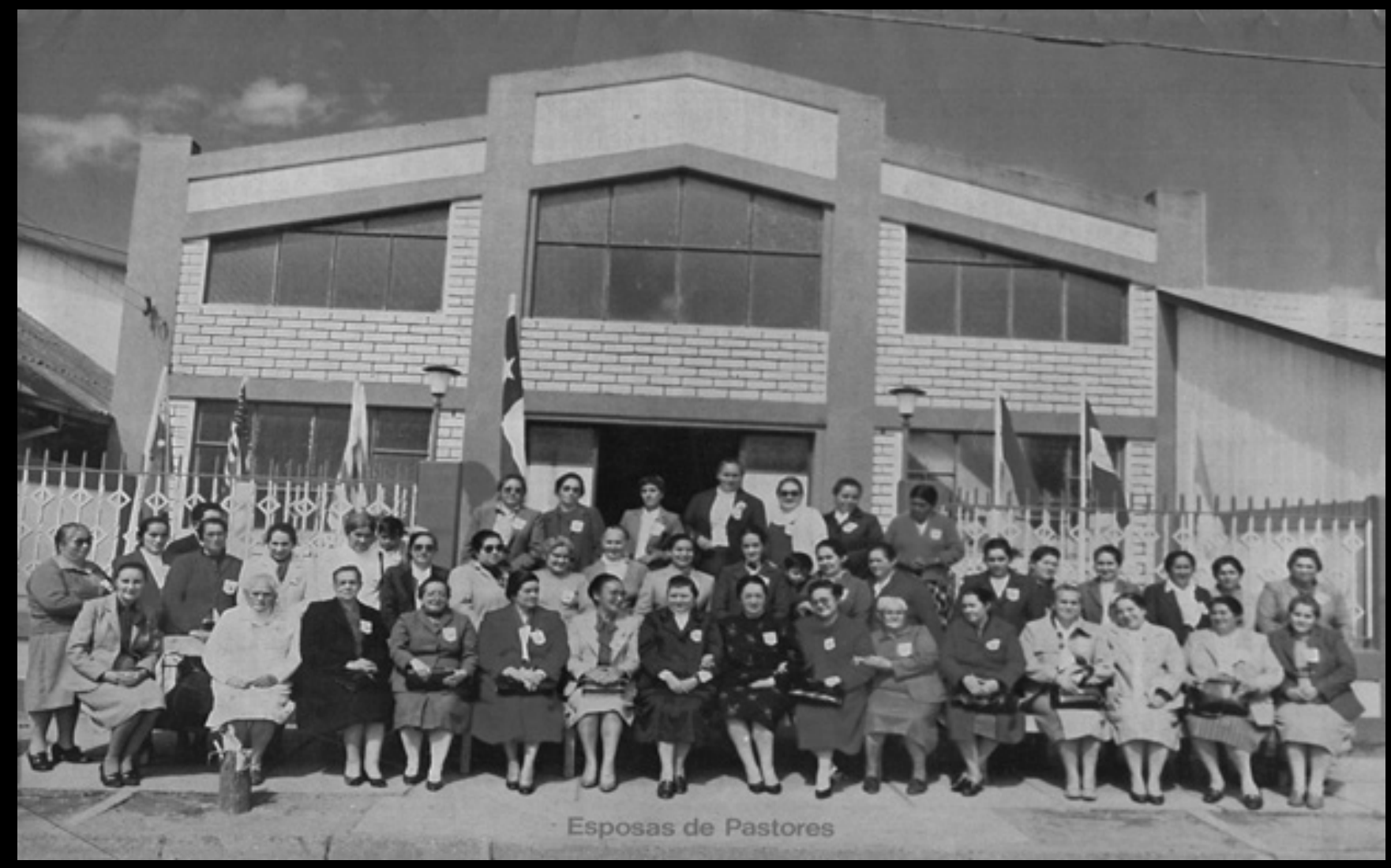




\section{Las pastoras pentecostales: metáforas sobre el liderazgo femenino \\ en la Iglesia Evangélica Pentecostal (1972-2001)}

Female pentecostal pastors: metaphors about women's leadership in the Pentecostal Evangelical Church (1972-2001)

As pastoras pentecostais: metáforas sobre a liderança feminina na Igreja Evangélica Pentecostal (1972-2001)

\section{Miguel Ángel Mansilla Agüero}

Instituto de Estudios Internacionales (INTE), Universidad Arturo Prat

(Santiago de Chile, Chile)

mansilla.miguel@gmail.com

\section{Luis Orellana}

Instituto de Estudios Avanzados (DEA),

Universidad de Santiago de Chile (USACH)

(Santiago de Chile, Chile).

luis_ubl@yahoo.com
El presente artículo está patrocinado y financiado por el proyecto de investigación posdoctoral CONICYT-FONDECYT, n. ${ }^{\circ}$ 3120162, Chile.

\section{Resumen}

Este artículo trata sobre los roles del liderazgo femenino en los movimientos revivalistas y pentecostales, para lo cual se analizan las metáforas construidas por los pentecostales chilenos sobre el rol de las pastoras. Nos centramos fundamentalmente en los relatos mortuorios, publicados en la Revista Fuego de Pentecostés entre los años 1972-2001, en los que aparecen las representaciones sobre las pastoras destacadas en cinco concepciones: esposa de pastor, predicadoras, copastoras, madres y visitadoras sociales.

\section{Abstract}

This article discusses women's leadership roles in the revivalist and Pentecostal movements, for which the metaphors built by Chilean Pentecostals on the role of female pastors are analyzed. We focus primarily on the mortuary stories, published in the Revista Fuego de Pentecostés between 1972-2001, in which representations of the prominent female pastors appear in five concepts: a pastor's wife, preachers, copastors, mothers and social workers.

\section{Resumo}

Este artigo trata sobre os papeis da liderança feminina nos movimentos revivalistas e pentecostais para o qual são analisadas as metáforas construídas pelos pentecostais chilenos sobre o papel das pastoras. Centramo-nos fundamentalmente nos relatos mortuários publicados na Revista Fuego de Pentecostés entre os anos 1972-2001, nos que aparecem representações sobre as pastoras destacadas em cinco concepções: mulher de pastor, pregadoras, copastoras, mães e visitantes sociais.

\section{Palavras chave}

pastora; pregadora; pentecostalismo; metáforas

\section{pastora; predicadora; pentecostalismo;} metáforas

\section{Keywords}

female pastor; female preacher; Pentecostalism; metaphors 


\section{Introducción}

Encontramos distintas investigaciones sobre los pastores pentecostales chilenos ${ }^{1} \mathrm{y}$ también sobre el predicador pentecostal ${ }^{2}$, mientras que los estudios sobre las pastoras son escasos. Por tal razón, este trabajo tiene como objetivo describir e interpretar los roles pastorales, como líder religiosa, de la esposa del pastor, en especial en la Iglesia Evangélica Pentecostal (IEP) ${ }^{3}$, por ser una de las iglesias madre y mejor consolidada institucionalmente del pentecostalismo chileno. Es decir, nos preocuparemos de los roles públicos de las mujeres como pastoras y predicadoras, funciones que están explícitas en los mismos relatos y biografías que aparecen en la Revista Fuego de Pentecostés ${ }^{4}$ pero que esta iglesia, desde lo institucional, no reconoce. Las fuentes documentales de esta indagación se sustentan en las necrologías de las mujeres pentecostales esposas de pastores que aparecen en la revista de la iglesia, entre 1972 a 2001 y para ello sometemos a un análisis los relatos referidos a ellas posmuerte.

En los últimos 25 años en la literatura del ámbito continental se observa una mayor cantidad de

1 Cristian d’Epinay, El refugio de las masas: estudio sociológico del protestantismo chileno (Santiago: Pacífico, 1968); Hans Tennekes, El movimiento pentecostal en la sociedad chilena (Ámsterdam: Facultad de Antropología Cultural y Sociología No Occidental. Universidad Libre de Ámsterdam/cIREN, 1985); Irma Palma, En tierra extraña. Itinerario del pueblo pentecostal chileno (Santiago: Amerindia, 1988); Manuel Ossa, Espiritualidad popular y acción política. El pastor Víctor Mora y la Misión Wesleyana Nacional. 40 años de historia religiosa y social (1928-1969) (Santiago: Rehue, 1990); Ana Guevara, «Movimiento protestante en comunidades indígenas. Testimonio de vida y fe», en Cuarto Congreso Chileno de Antropología: sociedad moderna, globalización y diferencia (Valdivia, 2009); Miguel Mansilla, «Irán andando y llorando llevando la semilla. Las imágenes de los pastores pentecostales a través de la muerte y la memoria 1909-1950», Revista Pandora, n. 25 (diciembre de 2010). http://revistapandorabrasil.com/revista_pandora/ religiao/texto_5.pdf. Consultado el 16 de marzo de 2014).

2 Carmen Galilea, El predicador pentecostal (Santiago: CISoc-BELLARMINo, 1991); Miguel Mansilla, «Nacidos en la calle: de la construcción bestial del predicador callejero a su construcción como patrimonio cultural», Revista Si somos Americanos, 2006.

3 La Iglesia Evangélica Pentecostal junto a la Iglesia Metodista Pentecostal de Chile hunden sus raíces en el avivamiento pentecostal de 1909 en Valparaíso. Por tanto, estas dos iglesias son las madres del pentecostalismo chileno. Para una historia del pentecostalismo chileno véase: Luis Orellana, El fuego y la nieve: historia del movimiento pentecostal de Chile 1909-1932 (Concepción: Ceep ediciones, 2008).

4 Es una revista que publica la Iglesia Evangélica Pentecostal desde 1927 siendo continuadora de la Revista Chile Pentecostal (1910-1926) la que a su vez es continuadora de la Revista Chile Evangélico (1909). trabajos sobre la mujer pentecostal ${ }^{5}$, lo que contrasta con la escasez de trabajos sobre las mujeres esposas de pastores, en general, y en particular en la IEP. Solo se encuentran algunos trabajos significativos de la antropóloga argentina Mónica Tarducci quien, desde el feminismo, aborda el rol de las pastoras ${ }^{6}$, destacando la precariedad del liderazgo religioso de las pastoras pentecostales en Argentina ${ }^{7}$.

Existen distintas investigaciones referidas a la participación de la mujer en el pentecostalismo ${ }^{8}$, de las cuales se pueden distinguir dos posiciones teóricas: una respecto a la reproducción cultural y otra sobre la resistencia cultural. Desde la perspectiva de la reproducción cultural se considera que «la religión pentecostal refuerza el rol tradicional de las mujeres, a través de las prácticas y de las representaciones que son compartidas en la comunidad $»^{9}$, basadas en la manifestación bíblica de «Dios, la cabeza del hombre; el hombre, la cabeza de la mujer» ${ }^{10}$, la cual se aplica

5 David Martín, «Otro tipo de revolución cultural: el protestantismo radical en América Latina», Revista de Estudios Públicos, n. 44 (1991); Rosa Mendoza, «Pentecostalismo popular en Akil, Yucatán», Mexicana del Caribe vII, n. 014 (2002): 105-144; Carlos Garma, Buscando el espíritu. Pentecostalismo en Iztapalapa y la ciudad de México (México: uam y Plaza Valdés Editores, 2004); Otto Maduro, «Notas sobre pentecostalismo y poder entre inmigrantes latinoamericanos en la ciudad de Newark», Horizonte Antropológico 13, n. ${ }^{\circ} 27$ (2007): 13-35; Elizabeth Juárez, «Las hijas de Eva. De la normatividad a la trasgresión». En Más allá del espíritu, acciones y prácticas en iglesias pentecostales (México: CIESAS-Colegio de Michoacán, 2007), 149-183.

6 Mónica Tarducci, «Estudios feministas de religión: una mirada muy parcial», Cuadernos Pagu Universidad de Campinas (2001): 97-114.

7 Mónica Tarducci, «Solo respondo al llamado de Dios. El precario liderazgo de las pastoras pentecostales», Revista de Antropología Iberoamericana, n. 40 (marzo-abril, 2005).

8 Sonia Montecino, «Caminar con el espíritu: perspectivas de género en el Movimiento Evangélico Pentecostal», Centro de Estudios Públicos, n. 87 (2002): 73-103; Fabiola Ibáñez, «Dios, la cabeza del hombre; el hombre, la cabeza de la mujer. Una aproximación a las relaciones de género en la iglesia evangélica pentecostal» (Tesis de pregrado, Universidad Arturo Prat, Iquique, 2003); Rosa Andrade, «Manos que sanan. Experiencia de salud en mujeres pentecostales chilenas», Cultura y Religión 2, n. 3 (2008). www.revistaculturayreligion.cl (consultado el 2 de abril de 2013); Martín Lindhardt, «Poder, género y cambio cultural en el pentecostalismo chileno», Cultura y Religión 3, n. 2 (2009): 94-112. www.revistaculturayreligion.cl (culsultado el 2 de abril de 2013); Zicri Orellana, Mujeres pentecostales: construcción del género a través de la experiencia religiosa (Santiago de Chile: Editorial al Aire Libre. Tomé, 2010); Zicri Orellana, «La iglesia pentecostal: comunidad de mujeres», Cultura y Religión 3, n. ${ }^{\circ}$ 2. (2009): 119-132. (consultado el 2 de abril de 2013).

9 Josefina Hurtado, «Mujer pentecostal y vida cotidiana», en Huellas, Seminario Mujer y Antropología (Santiago de Chile: CEDEM, 1993), 76. 10 Ibañez, «Dios, la cabeza del hombre», 25. 
particularmente a la conformación de la familia y a las pautas de socialización. Se reconoce que en el pentecostalismo las mujeres pueden ampliar sus horizontes agregando a lo materno, como símbolo de constitución y realización femenina, la filiación a una comunidad y la dignidad de su condición. Sin embargo, estos cambios no implican necesariamente la mutación de las relaciones tradicionales de género. Las mujeres, no obstante, pueden utilizar la retórica de la igualdad gracias a la interpretación bíblica, para contrarrestar el dominio masculino ${ }^{11}$. Desde esta perspectiva se presenta a una mujer pasiva y conciliadora, sin manifestar ningún tipo de resistencia y demandas sobre el patriarcado religioso.

La segunda perspectiva, desde las teorías de la resistencia, considera que la ideología religiosa pentecostal brinda soluciones a las mujeres al integrarlas a una comunidad solidaria ${ }^{12}$ en la que cumplen un rol fundamental como protagonista en los ritos de sanación al interior de las comunidades pentecostales ${ }^{13}$. Esta función permite superar la relación de dependencia con el hombre a través de la participación en la vida eclesiástica, espacio público que les permite actuar como sujeto religioso autorizado. $\mathrm{Su}$ poder y autonomía deriva de su relación espiritual con Jesús ${ }^{14}$. Si bien las mujeres amplían su horizonte de vida al ampliar sus funciones sociales (evangelización), este horizonte sigue estando limitado por los roles tradicionalmente asignados a las mujeres; metafóricamente se insertan en la representación de una gran familia espiritual que tiene a hijos e hijas repartidos en el mundo y en la que una gran madre no se cansa de esperar, ayudar, confiar y convocar a los hijos perdidos, lo que exige grandes esfuerzos para traerlos de nuevo al hogar. Estas tareas simbólicas, naturalizadas e invisibilizadas, se constituyen en su límite y confinamiento, evitando el desarrollo de su potencial humano ${ }^{15}$. Desde esta perspectiva se muestra el potencial transformador de la mujer pentecostal al considerarla como un sujeto religioso, que

11 Montecinos, «Caminar con el espíritu», 72.

12 Slootweg Hanneke, Mujeres pentecostales en Chile: un caso en Iquique (Iquique: TER, 1989), 9.

13 Andrade, «Manos que sanan», 55.

14 Lindhardt, «Poder, género y cambio».

15 Orellana, Mujeres pentecostales; Orellana, «La Iglesia Pentecostal». reflexiona, se comunica y lucha por transformar su condición social tanto en el hogar como en el templo, aunque esta lucha solo la realiza desde una posición marginal sin afectar la homogeneidad masculina en el liderazgo religioso.

Ambas posturas teóricas han contribuido significativamente al análisis de la mujer en el pentecostalismo chileno, pero no así al liderazgo femenino religioso, debido a que presentan limitaciones epistemológicas, teóricas y metodológicas.

En lo epistemológico presentan: a) una concepción homogénea de la mujer pentecostal considerada solo un sujeto pasivo y silente, sometida y determinada por las estructuras eclesiales. Esta concepción ha impedido el interés por el rol que cumplen las mujeres como pastoras. Se ha preocupado de observar elementos opresivos hacia la mujer, considerada como un sujeto laico, sin espacio ni acceso al liderazgo religioso. Mientras, nosotros optaremos por un modelo productivista, entendiendo que las mujeres no solo reproducen y resisten modelos dominantes, sino que crean espacios de participación y de ejercicio del poder religioso, solo que quedan invisibilizados o enmascarados. b) En segundo lugar, y en consonancia con Giddens, encontramos un excesivo pastorcentrismo, dejando de lado «la reflexividad, como propiedad distintiva de la especie humana» ${ }^{16}$. El único sujeto-agente que aparece en estas investigaciones es el pastor, mientras que los laicos y mujeres son sujetos-actores que solo reproducen, recitan y obedecen libretos escritos por el pastor.

En el ámbito teórico, dada su influencia funcionalista, presentan cuatro limitaciones: a) el constante constreñimiento del sujeto laico y femenino al poder pastoral y eclesiástico; b) desatención de la condición conflictual, resistente y negociada de las normas, creencias y prácticas religiosas y su posterior incidencia social; c) preocupación solo por el liderazgo, poder y autoridad explícitos y declarados, dejando de lado lo latente e implícito; d) la asunción de un carácter pasivo o insignificante del liderazgo femenino, negando su capacidad resistente, reflexiva y propositiva. Nosotros, en cambio, optaremos por un enfoque

\footnotetext{
16 Anthony Giddens, Las nuevas reglas del método sociológico. Crítica positiva de los métodos comprensivos (Buenos Aires: Amorrortu, 1993), 21.
} 
teórico, en palabra de Michel Löwy ${ }^{17}$, vinculado al cristianismo liberacionista, específicamente la teología feminista.

Por último, en términos metodológicos, no existe acceso ni análisis sistemático y significativo de las revistas publicadas por los mismos pentecostales, algunas de las cuales se vienen publicando desde 1910, con la excepción y el acceso parcial que han tenido el historiador Luis Orellana y el sociólogo y antropólogo Miguel Ángel Mansilla. Esto no ocurre por desconocimiento, ya que algunos autores las citan, sino por desconfianza en las fuentes evangélicas. En cambio, nosotros recurriremos a la revista Fuego de Pentecostés ${ }^{18}$ tanto por ser la revista oficial de la IEP, que se viene publicando desde 1928 y constituye actualmente la principal fuente de información disponible sobre la marcha de esta iglesia, como por ser esta una entidad que no reconoce la función pastoral de la mujer y la esposa del pastor no goza del reconocimiento de pastora como sí ocurre en la mayor parte del pentecostalismo chileno. No obstante, dado que al revisar el formato de este medio no encontramos descripciones de la «vida pastoral de las mujeres», recurrimos a «la vida de las mujeres que después de la muerte es reconocida su labor pastoral», es decir a las notas necrológicas; por el espacio nos preocuparemos desde la década de 1970. Solo así pudimos encontrar información para develar el poder religioso de la mujer desde el uso de la palabra y la administración eclesiástica. Pese a que no son las mujeres las que hablan, sino una interpretación institucional, al menos las descripciones veladas en las metáforas recuerdan el trabajo y la autoridad pastoral de las mujeres.

Primero, haremos un «trabajo arqueológico» sobre el liderazgo femenino en movimientos revivalistas y carismáticos, con la finalidad de mostrar la fuerte presencia de la mujer en la fundación de movimientos pneumatológicos, pero una vez que se institucionaliza, el rol de la mujer se invisibiliza, como ocurrió en el caso del pentecostalismo chileno. Luego recurriremos a desenmascarar las metáforas referidas a las mujeres líderes para

17 Michael Löwy, Guerra de dioses: religión y política en América Latina (México: Siglo xxI, 1999), 48.

18 Esta revista es de publicación mensual, en 2013 superaba las 1000 ediciones. escudriñar y develar el acceso al poder y la administración del trabajo religioso. Para tal objetivo, el corpus como fuente de información fundamental está formado por la sección necrológica de la Revista Fuego de Pentecostés entre 1972 y 2001.

\section{Mujer: carisma y liderazgo religioso}

La afirmación general de que las mujeres son marginales y excluidas en las iglesias hace referencia a diversas situaciones: están impedidas de la ordenación o cuando se permite se hace de manera incompleta (ordenadas y relegadas a templos pequeños) lo que no las deja incidir en posibles cambios en la naturaleza del ministerio ${ }^{19}$. A pesar de ello, es destacable el rol de la mujer en los movimientos religiosos revivalistas, carismáticos o místicos, mientras que cuando el movimiento se transforma en una denominación de renombre las mujeres son olvidadas ${ }^{20}$. Varias denominaciones protestantes ${ }^{21}$, y pentecostales en particular, han sido fundadas por mujeres, destacándose dos momentos en los que las mujeres han sido líderes religiosas en los movimientos pneumatológicos más importantes de los últimos dos siglos: el movimiento de santidad o revivalista y el movimiento pentecostal.

El amplio movimiento revivalista en Estados Unidos de comienzos del siglo xIX atrajo a diversas mujeres que tuvieron la oportunidad de participar activamente dando testimonio público de su fe y predicando ${ }^{22}$. Asumieron su papel de guardianas

19 Tarducci, «Estudios feministas», 106.

20 Tarducci, «Solo respondo al llamado».

21 Encontramos tres denominaciones protestantes fundadas o cofundadas por mujeres: 1) Los cuáqueros, Margaret Fell Fox (16141702) es recordada como la esposa de George Fox y fundador de los cuáqueros. 2) Catherine Booth cofundadora de la Iglesias Ejército de Salvación, en Londres en 1878 junto a su esposo William Booth. 3) La Iglesia del Nazareno fue fundada en 1908 por la fusión de la Iglesia Pentecostal del Nazareno, con la Iglesia del Nuevo Testamento de Cristo. Una cofundadora de la Iglesia del Nuevo Testamento de Cristo fue la Reverenda Mary Lee Cagle.

22 En la web encontramos una página del protestantismo norteamericano fundamentalista en la que se refiere a las mujeres que lideraron el movimiento de santidad y el pentecostalismo: «El diablo da gracias a los hombres de estas mujeres famosas. Estos hombres permitieron que sus esposas y mujeres de sus iglesias, ir en contra de las Escrituras y usurpado la autoridad masculina, estas mujeres han hecho más daño a la verdad del cristianismo bíblico que el diablo podría haber hecho por su cuenta. Los hombres permisivos con el liderazgo femenino, no solo han destruido un país, han destruido las palabras de Jesucristo en miles y miles de hogares en 
de la moral, tuvieron la oportunidad de hablar en público y organizarse ${ }^{23}$. A pesar de la corta existencia que tuvo el movimiento revivalista, localizado inicialmente en Norteamérica, tuvo efectos políticos, sociales y culturales destacados. Se extendió por todo el mundo transformando su carácter religioso a secular e incidiendo en un amplio abanico de reconocimiento de derechos humanos, como la lucha en contra de la discriminación racial, el movimiento de temperancia, la formación de los grupos de «alcohólicos anónimos» y el movimiento sufragista ${ }^{24}$. En el ocaso del movimiento revivalista a finales del siglo xIx y en los albores del siglo xx, surgió con fuerza el pentecostalismo, iniciado también por mujeres y continuado en buena parte por hombres y mujeres afroamericanos. Sin embargo, son los hombres los recordados como fundadores de dicho movimiento, olvidando la iniciativa y acción de las mujeres.

María Beulah Woodworth-Etter (1844-1924)25 fue una predicadora que comenzó su trabajo de manera itinerante, sin el apoyo de su marido, transgrediendo así las normas sociales de su tiempo. Esto implica una rebeldía precoz para la épo$\mathrm{ca}$, en la que ya existe «un atrevimiento, que va más allá de los cánones tradicionales de la exégesis tradicional $»^{26}$. Desde el comienzo de su actividad como predicadora manifestó experiencias extáticas, taumatúrgicas y catárticas. Puede ser considerada como precursora del movimiento pentecostal en el mundo. En 1912 se constituye como una predicadora pentecostal. Jacobsen destaca que Woodworth-Etter en 1916 publica su libro Señales y maravillas que Dios ha realizado en el ministerio durante cuarenta años, en el

América y esta destrucción ha viajado a millones de personas en todo el mundo. Estoy seguro de que esos miles de cristianos que pasaron muchos años de su vida siendo sometidos tortura espirituales, les encantaría saber que por el fruto de su cobardía, hoy se han engañado a millones de personas en todo el mundo». Ver: http://scatteredchristians.org/PentecostalWomen.html. A pesar de que esta denominación protestante denosta el liderazgo femenino, resulta significativo porque recopila un listado de mujeres de los movimientos de santidad y del pentecostalismo norteamericano.

23 Tarducci, «Solo respondo al llamado».

24 Angela Davis, Mujeres, Raza y Clases (Madrid: Akal, 2004).

25 María Beulah Woodwoth-Etter (1844-1924) destacada predicadora pentecostal de las Asambleas de Dios en Estados Unidos. http://ag.org/enrichmentjournal_sp/200901/200901_140_Woodworth-Etter.cfm

26 Nancy Cardoso, «Pautas para una hermenéutica feminista de la liberación», RIBLA, n. ${ }^{\circ} 25$ (1996), 5. que realiza una defensa del derecho de las mujeres a predicar y a ser reconocidas como profetas y, por lo tanto, deben hacer caso a ese llamado y superar las limitaciones impuestas por los hombres $^{27}$. Obviamente esto produjo un gran revuelo, porque la hermenéutica androcéntrica y patriarcal de la Biblia se sintió amenazada y por eso se apresuró a buscar legitimidad para marginar a la mujer en la iglesia y la teología ${ }^{28}$.

Pandita Ramabai (1858-1922) conoció el cristianismo cuando viajó a Inglaterra, donde fue recibida por la Iglesia Anglicana Sisterhood de Wantage. En 1883, en dicha iglesia, Pandita fue testigo de la obra a favor de las madres solteras. Allí, junto con su hija, recibió su bautismo y ostentó la cátedra de sánscrito en el Chelteham Ladies Collage, comenzando a dar conferencias sobre la condición de las mujeres en la India. Escribió The High Caste Hindu Woman, obra que tuvo una importante repercusión en Inglaterra y en Estados Unidos y que le permitió financiamiento para su proyecto social en India y tradujo la Biblia al marathi. En 1888 abrió el Hogar de la Viuda en Bombay, denominándolo Morada de Sabiduría. Como destaca Sepúlveda, el Movimiento del Espíritu de Gales, que tuvo lugar en 1904, generaría un gran impacto espiritual en Pandita Ramabai. Un año después, mientras estaba en Mukti, tuvo una experiencia carismática y pentecostal con el Espíritu Santo. Ella ha sido catalogada como uno de los más grandes ejemplos de cristianismo en acción ${ }^{29}$. A pesar de que en Pandita no hay una hermenéutica feminista que ponga en cuestión teológicamente el discurso religioso patriarcal ${ }^{30}$, sí encontramos un liderazgo femenino carismático, impensado

27 Jacobsen Douglas, «María Beulah Woodworth-Etter (1844-1924). El lugar de una mujer está en el púlpito», en Enrichment Journal, 2009. http://ag.org/enrichmentjournal_sp/200901/index.cfm (consultado el 5 de mayo de 2013).

28 Elsa Tamez, «Pautas hermenéuticas para comprender Ga. 3,28 y 1 Co. 14, 34», RIBLA, n. 15 (1992): 9-18.

29 Juan Sepúlveda, De peregrinos a ciudadanos. Breve historia del cristianismo evangélico en Chile. (Santiago: Fundación Konrad Adenauer; FET y CTE, 1999), 22-23.

30 Adriana Méndez-Peñate, «Una espiritualidad para la mujer», RIBLA, n. 13 (2000), 87-103; Alice Dermeience. «Theologíe de la femme et theologie feministe». Revué Thelogique the Louvain, $n .^{\circ} 31$ (2000): 492-523; Cardoso, «Pautas para una hermenéutica»; Tamez, «Pautas hermenéuticas».

Las pastoras pentecostales: metáforas sobre el liderazgo femenino / Miguel Ángel Mansilla Agüero, Luis Orellana / 87 
para la época, aunque sea reproduciendo los estereotipos maternalistas.

Alice Eveline Luce inicialmente fue nombrada misionera en la India por la Iglesia de Sociedad Misionera, aunque destacó por el trabajo realizado en Estados Unidos, donde fundó junto a Henri Clio Ball las Asambleas de Dios ${ }^{31}$. McGee señala que ella fue ordenada como ministra en 1915 y empezó su obra evangélica entre los latinos de la ciudad de Los Ángeles. Además, organizó programas de capacitación y entrenamiento para pastores y evangelistas a fin de evangelizar a los hispanos en Estados Unidos, fundando para tal efecto el Instituto Bíblico Berea, en la ciudad de La Puente, California ${ }^{32}$. Como Alice Eveline se casa con Henri Clio Ball pasa a un segundo plano, quedando solo como esposa y no como líder. De esta manera ocurre lo de siempre, el matrimonio inivisibiliza el liderazgo femenino ${ }^{33}$.

Aimee McPherson fue predicadora itinerante en Canadá y Estados Unidos. En 1916 en compañía de su madre, Mildred Kennedy, recorre el sur de los Estados Unidos predicando en automóvil, denominándolo el «Coche del Evangelio». En 1917 creó su propio periódico, La Llamada Nupcial, para el cual escribió muchos de sus artículos. Junto con sus predicaciones itinerantes, recaudó fondos para la construcción de una gran iglesia en Los Ángeles, Angelus Temple, construida en 1923. El templo tenía una capacidad para más de cinco mil personas y conseguía llenarla tres veces al día todos los días de la semana; fue llamada la Iglesia del Evangelio Cuadrangular ${ }^{34}$. Durante la década de 1920 el pentecostalismo no era popular en Estados Unidos, por lo que McPherson contribuyó a su divulgación a través de las manifestaciones de la

31 Las asambleas de Dios es la denominación pentecostal más grande del mundo y dan mucho énfasis tanto al estudio de la Biblia como a la oración y las misiones. Actualmente las asambleas de Dios cuentan con 60.000 .000 de miembros y 307.553 iglesias en más de 212 países. Es la denominación pentecostal a su vez que en distintos países ordena mujeres como pastoras, aunque depende de cada país.

32 Gary McGee, «Alice Eveline Luce», en Biographical Dictionary of Christian Missions, ed. Gerald H. Anderson (Nueva York: Macmillan, 1999), 414.

33 Tarducci, «Solo respondo».

34 Esta denominación pentecostal se caracteriza más bien por sus iglesias pequeñas. Su membrecía mundial supera los 6 millones con casi 100.000 iglesias en 125 países diferentes. Sus oficinas corporativas centrales se encuentran en Los Ángeles, California. fe y la sanidad en los sermones, manteniendo un museo que contenía las muestras de la sanación (muletas, sillas de rueda). Inició emisiones radiales y consiguió fundar la emisora KFSG, convirtiéndose en la primera mujer con una licencia de emisión por la Comisión Federal de Radio. El gran legado de McPherson es que la Iglesia del Evangelio Cuadrangular se caracteriza por su inclusión de la mujer en el pastorado ${ }^{35}$.

Por último, Kathryn Johanna Kuhlman (19071975) fue también una destacada predicadora itinerante. En 1935, abrió el Tabernáculo del Avivamiento de Denver, con un enorme cartel que decía: «La oración cambia las cosas». El salón tenía capacidad para dos mil personas sentadas. Durante los siguientes años, miles de personas asistieron a las reuniones, realizándose cultos todas las noches, excepto los lunes. Fue una mujer la que organizó grandes campañas de sanidad y milagros, influyendo en las generaciones de televangelistas norteamericanos ${ }^{36}$.

De las mujeres líderes, Aimee McPherson y Kathryn Kuhlman son las que cuentan con más admiración y rechazo. Sobre ellas se han construidos leyendas que expresan tanto el reconocimiento y la exaltación, como el rechazo y la injuria. Pueden ser tratadas como brujas, hechiceras o rameras. Basta con googlear sus nombres para adentrarse al mundo de los mitos ultrajados que cargan estas mujeres. Guy Bechtel señala, al respecto, que

[...] la mujer, no solamente es considerada, mediocre o insignificante. Es puta. Es decir, mujer lúbrica que no puede evitar fornicar y que busca el placer sin parar [...] y al ser inferior y lasciva, por tanto proclive a placeres y venganzas, forzosamente está predispuesta a la brujería. Siempre, en todas las épocas del cristianismo, la mujer ha exhalado un perfume demoníaco ${ }^{37}$.

Quizás para los protestantes y pentecostales la mujer ideal y virtuosa es la que obedece en silencio,

35 Tomado de la página de la denominación Pentecostal Iglesia del Evangelio Cuadroangular. http://www.foursquare.org/landing_pages/8,3.html (consultado el 5 de octubre de 2012).

36 Virgilio Zaballo, Una nube de Testigos. Un compendio de la historia del cristianismo a través de muchos de sus protagonistas (Londres: Fundación DCI, 2007), 82. http://www.scribd.com/doc /23193074/Virgilio-Zaballos-Una-nube-de-testigos (consultado el 25 de abril de 2013).

37 Guy Betchel, Las cuatro mujeres de Dios: La puta, la bruja, la santa y la tonta (Madrid: Zeta, 2001), 139. 
cuanto más silente y sumisa es, más pureza exhala; acogiéndonos al dicho diríamos que «a la mujer silenciosa su santidad se le escucha a gran distancia». La mujer que acepta y cumple con los roles tradicionales y que colabora en el mantenimiento del templo es considerada como una mujer de Dios. En cambio, las predicadoras y pastoras, especialmente aquellas que tienen éxito, son sospechosas de que no es el Espíritu de Dios sino el espíritu demoníaco las que las dirige. Se admite el liderazgo femenino en la gestación del movimiento religioso, en la construcción del templo y en la convocatoria de feligreses, para posteriormente entregarlo a la dirección del varón. Esto es así porque, como dicen Moya y Renard, siempre lo puro se asocia a lo divinomasculino y lo impuro-humano a lo femenino ${ }^{38}$.

La mujer también fue pionera en el nacimiento de varias denominaciones pentecostales en América Latina. En México, el pentecostalismo tiene sus primeras manifestaciones en 1914 en los estados del norte colindante con Estados Unidos, destacando la labor de Ramona Carvajal, María de los Ángeles Rivera y Anna Sanders ${ }^{39}$. En Cuba el pentecostalismo nació por el trabajo de Anna Sanders y Haniet May Kelty, encargadas por las Asambleas de Dios en 1932. En Colombia, Charles Berchtold y su esposa Clara, ambos estadounidenses, llegaron en 1932. Ese año también llegó desde Estados Unidos Eleanor Berchtold, quien era hermana de Charles Berchtold, para apoyarlos. Maruja Correa fue la primera persona en ser ganada por los Berchtold, y a su vez Maruja se ganó a su hermana Alicia. Las dos se destacaron como maestras de niños en la escuela dominical. Maruja Correa y Eleanor Berchtold trabajaron como misioneras en poblaciones vecinas a Málaga, tales como Enciso, Susa y Belén, quedaron encargadas de la obra en Enciso.

En Argentina llegó Alice Wood en 1910, la primera misionera que da comienzo a una presencia pentecostal permanente en el país. La importancia

38 Marcia Moya y Helmut Renard, «La mujer que sin nombre y sin hombre se salva a sí misma. 'Mujer, tu fe te ha salvado'», RIBLA, $\mathrm{n}$. 49 (2004): 46-57.

39 Carolina Rivera, «La comunidad eclesial y la comunidad moral: ¿dos realidades en sintonía?», en Más allá del espíritu. Actores, acciones y prácticas en iglesias pentecostales (México: CIESA y El Colegio de Michocán, 2007), 119. del ministerio de Alice Wood radica en ser pionera en el establecimiento de la primera iglesia pentecostal en Argentina. Además, pasaron por ella muchos de los que serían los primeros líderes nacionales. A pesar de estos antecedentes, el liderazgo de esta mujer ha sido ampliamente invisibilizado e ignorado ${ }^{40}$. En Chile, como dice Sepúlveda, durante la primera mitad del siglo xx gran parte del personal misionero anglicano estaba integrado por mujeres, hasta el punto en que en la década de 1930 y 1940, los seis internados de la Misión Araucana fueron dirigidos por mujeres, lo que tuvo un gran impacto en la educación de las niñas mapuches. Este predominio de mujeres en el personal misionero fue en gran medida resultado de la «generación de solteras» que produjo la Primera Guerra Mundial, muchas de las cuales optaron por una vocación misionera ${ }^{41}$.

Las mujeres tuvieron un protagonismo sin precedente en el pentecostalismo chileno ${ }^{42}$. Al igual que sucedió en otros países, la institucionalización del movimiento supuso la invisibilidad de la mujer ${ }^{43}$ y su dependencia del esposo (pastor). En el templo y el hogar eran pastoras, en calidad de esposas, teniendo acceso a la palabra pregonando el evangelio. A pesar de que ellas son sistemáticamente silenciadas, en las revistas (Fuego de Pentecostés) de las que extrajimos los relatos se recoge la vida de las mujeres a través de relatos construidos por otros. Las mujeres que siempre callaron en la congregación son exaltadas después de su muerte. A través de estos relatos es posible conocer la vida de las pastoras y las características de su liderazgo, mediante las representaciones que la congregación realiza sobre ellas.

\section{Las pastoras pentecostales}

El pastorado femenino en el pentecostalismo es antiguo, controlado e invisible, surge desde la experiencia carismática. Es decir, existe la creencia que es el Espíritu Santo quien entrega los dones espirituales, sin importar el sexo, condición social o edad, por lo tanto Dios también puede llamar a

\footnotetext{
40 Tarducci, «Solo respondo al llamado».

41 Sepúlveda, De peregrinos a ciudadanos, 53.

42 Mansilla, «Nacidos en la calle».

43 Tarducci, «Solo respondo al Ilamado».
}

Las pastoras pentecostales: metáforas sobre el liderazgo femenino / Miguel Ángel Mansilla Agüero, Luis Orellana / 89 
hombres y a mujeres al ministerio pastoral. Esta es una creencia común

[...] en las religiones revivalistas o carismáticas, en donde, las mujeres tienden a surgir como ministras en los movimientos religiosos que no realizan un control sobre su clerecía y que dependen de una emoción religiosa auténtica y espontánea. Por eso los grupos evangélicos más laxos pueden ser pastoreados por mujeres ${ }^{44}$.

Las pastoras pentecostales son mujeres que asumen, al menos, cuatro roles: esposa, madre, predicadora y pastora.

\section{Esposa de Pastor}

E1 relato bíblico está lleno de parejas que, juntas, recorren el camino a Dios, apoyándose mutuamente, y buscan alcanzar la liberación. Es en la Biblia también (profetas, salmos, Pablo) donde se utilizan metafóricamente las riquezas y posibilidades del amor humano para referirse a la relación entre Dios y el hombre ${ }^{45}$. Sin embargo, la interpretación de estos relatos, referidos al amor conyugal y aplicados a las pastoras pentecostales quedan sumidos en la dependencia al esposo, lo que impide el ejercicio del liderazgo femenino. En los relatos que presentaremos a continuación, cuando se habla de pastora se hace referencia a la esposa del pastor, a su vínculo de dependencia matrimonial, en el que el liderazgo femenino se hace invisible y secundario, sin reciprocidad en tanto que el hombre no es conocido como el esposo de la pastora. Esta asimetría sumerge a la mujer en la dependencia conyugal; el atributo de la dirección de fe es asignado al varón, que acumula el poder, el prestigio y los privilegios:

Juanita Vda. de Seguel. Con fecha $1^{\circ}$ de julio de 1971, fue llamada a la presencia del Señor la hermana Juanita Vda. De Seguel, falleció a los 64 años de edad, 40 años trabajó en la obra del Señor y 36 ayudó y colaboró con su esposo, quien fuera el respetado Presbítero (Pastor) Leopoldo Seguel Seguel ${ }^{46}$.

Se reconoce que la mujer trabaja para la obra pentecostal en calidad de ayudante (subsidiaria) y colaboradora de su esposo-pastor. La idea de ayuda idónea en este contexto alude a la realización del mismo trabajo pastoral que el esposo, pero sin reconocimiento personal y en anonimato. El esposo es el pastor de la iglesia, mientras que la pastora realiza una labor solidaria de las funciones del esposo. Como señala Navia, las mujeres aparecen en este contexto como ayudantes y colaboradoras en el proceso de consecución del objetivo $^{47}$, pero sin llegar a ser coprotagonistas:

[...] nuestra apreciada hermana Sebastiana Miranda de Castillo, esposa de nuestro pastor Manuel Castillo [...] esta sierva de Dios dispuesta a ayudarle, poniendo todos sus esfuerzos y contraponiéndose a las adversidades que tuviera que afrontar por amor a la obra de Dios [...] el 20 de abril de 1969 nuestro amado pastor es trasladado a Puerto Montt, pudiendo ella resignarse a acompañarle a esta amada Iglesia que un día le viera llegar obedeciendo a los designios de Dios. Como un ramillete de flores nos ha dejado un ejemplo de una fiel cristiana y su espíritu selecto de sumisión a la voluntad de Dios, la hizo una idónea esposa y fiel colaboradora de nuestro amado pastor...siempre la veíamos en constante comunión con el Señor en oración y ayuno hasta el día de su partida, en que terminó su carrera con un día de cadena de oración y ayuno $[\ldots]^{48}$.

Como esposa de pastor es considerada sierva de Dios, expresión utilizada normalmente para los pastores. El siervo de Dios es el pastor. Sin embargo, la diferencia se presenta cuando se resalta en el carácter resignado de la mujer. La esposa es considerada en la medida que se subraya su aporte como ayudante y colaboradora pentecostal. $\mathrm{La}$ problemática se presenta en su relación como ayudante, ya que es concebida como alguien menor, aprendiz y que cuenta con un maestro-jefe. En esto se evidencia un dualismo simplista, reduccionista e impertinente respecto a la interpretación de las relaciones sociales, sobre todo en lo que respecta a las relaciones de género, en las que lo masculino y lo femenino se encierran en realidades separadas e irreconciliables, y el hombre representa un todo frente a la mujer como una parte dependiente y subordinada $a^{49}$.

Como mujer aparece asociada a dos ritos fundamentales: el ayuno y la oración; el ayuno

\footnotetext{
47 Navia, «La mujer en la Biblia».

48 Revista Fuego de Pentecostés, n. 604 (diciembre de 1979): 15. 49 Simona Beauvoir, El segundo sexo (Madrid: Cátedra, 1998).
} 
vinculado a la purificación y al sacrificio y la oración como rito de intercesión social. Ambos ritos tienen que ver con el sacrificio por los otros, no son solamente ritos íntimos, evasivos, culposos y de refugio, sino que son de mediación e injerencia sobre la vida de los otros. Es decir, las esposas de pastores, como mujeres, siempre interceden y están preocupadas por los demás: sus hijos, su esposo, la iglesia y el mundo. Por último, también se destaca la metáfora «ramillete de flores» aludiendo a la idea de belleza pasiva, mostrada, de «mujer cortada» o extraída del jardín, que es la iglesia. Su vida es aromática y embellecedora, pero puramente contemplativa: es una ética estética, que es resaltada por su pasividad. $\mathrm{Al}$ mismo tiempo, guarda relación con la sanación, con dones terapéuticos administrados por las mujeres que permiten restablecer la salud física y mental. Esta metáfora se basa en la concepción del ser humano como una unidad psicosomática, en la que lo que importa es el enfermo y no la enfermedad, la persona y no su condición social.

La metáfora floral también se vincula a la función reproductiva de la mujer a través de las semillas en la reproducción de la palabra predicada. Las semillas contienen vida, germinan en sucesivas generaciones y sirven para la perpetuación y propagación de la especie. Así también solo a través de la propagación del mensaje es posible el nacimiento de una nueva generación de creyentes para el crecimiento y perpetuación de una comunidad religiosa. Por último, esta metáfora implica también su carácter social, así como las flores crecen juntas, las mujeres son no solo las propagadoras, sino también las que construyen al carácter comunitario de la religión.

No obstante estas mismas capacidades productivas y reproductivas de las metáforas florales aplicadas a las mujeres se transforman en recursos que impiden su promoción y ascenso al pastorado, ya que la catalogan como un ser bello y pasivo, pero incompetente por destino divino para dirigir y tener acceso al púlpito.

E1 Señor la llamó a su presencia a quien fuera esposa y fiel compañera, Sara Chacana de Moreno, un baluarte y fiel compañera. Fue una sierva útil y fiel defensora de la justicia y la verdad [...] nunca supo quejarse de pobrezas ni de dificultades para servir al Señor, mientras pudo hacerlo como fiel soldado pre- dispuesta al servicio que Dios le había encomendado en sus manos $[\ldots]^{50}$.

En esta esquela se destacan aspectos que también se resaltan en el pastor: metáfora arquitectónica y metáfora castrense (baluarte), metáfora del servicio (sierva útil), metáfora de la heroína (defensora de la justicia y la verdad) y metáfora bélica (fiel soldado).

La pastora se compara con una «metáfora arquitectónica» $\mathrm{y}$ «metáfora bélica» en el sentido de un muro flanqueado por el pastor. Según esta metaforización, la pastora es vista como situada estratégicamente para soportar y resistir los ataques exteriores, y aparece como la esposa del pastor (metáfora castrense) luchadora y difusora del evangelio.

La disposición al servicio es una extensión de su papel como sierva no solo de Dios, sino también del pastor, aunque realice actividades con aparente independencia. La mujer puede trabajar predicando y enseñando la Biblia en la congregación y en la calle; aconseja, enseña y guía a las mujeres de la iglesia, pero de manera informal, el púlpito le está prohibido. Su influencia en las decisiones del templo está destinada al pastor y no se expresan públicamente ${ }^{51}$. Se mueve en una imagen de luz y sombra. La luz vendría en la defensa de la justicia y la verdad, como responsabilidad social; las sombras la imposibilidad de reconocimiento público (prestigio).

De esta manera, el liderazgo femenino se vincula con lo que señala Méndez-Peñate: 1) una experiencia solidaria y de trabajo en común. Esto implica buscar mejores condiciones de vida y servicios, elaborando juntas cooperativas de consumo; 2) una experiencia fecunda, pascual-martirial, vitaldadora de vida, en el sentido de sostener no solo la iglesia, sino también la vida de los hogares, la vida de la Iglesia: 3) una experiencia evangélica,

50 Revista Fuego de Pentecostés, n. 625 (septiembre de 1981): 16. 51 Las mujeres, aún como esposas de pastores, han sido influyentes en los cambios religiosos, aspectos que han sido destacados por los mismos esposos. Algunas de esas frases se han transformado en verdaderos mitos. Sabina Wurmbrand es conocida por un conciso pero significativo diálogo: «Mi esposa y yo estábamos presentes en ese Congreso. Ella, que estaba sentada cerca de mí, me dijo: 'iRichard, levántate y limpia la cara de Cristo de tanta vergüenza! Están escupiendo en su cara'. Le dije: 'Si lo hago, pierdes a tu esposo'. Ella respondió: 'No deseo tener a un cobarde por esposo'». Richard Wurmbrand, Torturado por Cristo: La iglesia mártir de hoy (Londres: Hayfield Publishing co., 1979).

Las pastoras pentecostales: metáforas sobre el liderazgo femenino / Miguel Ángel Mansilla Agüero, Luis Orellana / 91 
creativa y femenina. Esto implica la búsqueda de distintas estrategias para compartir la fe y las creencias con los que sufren, con nuevas experiencias de ardor y pasión ${ }^{52}$.

Angelina Pacheco Lagos [...] esta humilde y sencilla mujer de Dios se caracterizó por su gran espíritu hospitalario ya que su hogar se convirtió en el hogar de todos sus hermanos que específicamente venían de los campos y disfrutaban de su cariño y atenciones [...] la casa pastoral era la casa de sus hermanos ${ }^{53}$.

Uno de los grandes desafíos que se le presentan a la esposa del pastor es la casa pastoral como una extensión del templo; así, el hogar a cargo de la esposa es una extensión al conjunto de la comunidad. La esposa del pastor se encarga de acoger a otros pastores, hermanos recomendados, personas necesitadas y hermanos de la propia congregación. La casa pastoral es una verdadera hospedería a cargo de la esposa; sus labores domésticas y el cuidado de la familia se extiende al conjunto de la congregación. Aunque la casa pastoral se le llama así porque es la casa del pastor, es la pastora quien la trabaja, ordena y atiende, por tanto su trabajo doméstico se torna anónimo. Esto se debe al lenguaje sexista que invisibiliza a las mujeres nombrándolas únicamente cuando constituyen un problema ${ }^{54}$.

\section{Co-pastora}

Hay dos características del pentecostalismo que facilitan la participación de las mujeres en la actividad eclesial: primero, la comunidad estaba organizada en células que se reunían en distintas casas de la ciudad; en segundo lugar, el ministerio era de tipo carismático. Como señala Foulkes, al asistir a una reunión en una casa, las mujeres se encontraban en un ambiente que se consideraba propio de ellas. El hogar se convierte en punto de reunión y de relación con la comunidad, donde practicaban sus dones y se preparaban para aquellos momentos en los que se reunía toda la iglesia en un solo local. Todos contribuían de alguna

52 Méndez-Peñate, «Una espiritualidad para la mujer».

53 Revista Fuego de Pentecostés, n. 827 (julio de 1998), 6-7.

54 Maribel Pertuz, «Carta a Filemón desde la perspectiva feminista», RIBLA, n. ${ }^{\circ} 28$ (1997): 37-43. manera al ministerio de la comunidad eclesial por medio de sus distintas capacidades y dones ${ }^{55}$.

[...] nuestra fiel y respetada hermana, Clarisa Suarez junto a su esposo en el año 1925, construyeron su casa habitación dedicando una pieza para alabar el nombre del Señor y luego empezaron a sembrar la preciosa semilla del Evangelio del Señor Jesucristo, trabajo que fue muy fructífero [...] Dios le dio la bendición espiritual, que en su casa naciera la iglesia de La Cisterna $[\ldots]^{56}$.

Lo que vemos aquí es algo que señala Pertenuz: el punto de partida del cambio posible no es el templo, donde los débiles, los pobres, los enfermos, las mujeres no tenían pleno acceso, sino la casa, donde están presentes los que no tienen derecho a la vida pública. La casa es también símbolo de la comunidad en la que se establecen nuevas relaciones y se descubre un rostro de Dios con características femeninas ${ }^{57}$. En la casa-templo la mujer tiene acceso a la palabra en el púlpito fugaz, espacio que le es negado en la iglesia.

La mujer es presentada como co-pastora, quien, junto a su esposo, comienza la obra pentecostal poniendo a disposición su casa como templo; también juntos comienzan predicando en la calle. Por otro lado, la misma metáfora agrícola aplicada al pastor es empleada a la pastora como sembradora de la semilla. Así, la pastora es una campesina, una obrera y un albañil; todas estas metáforas hacen relevante el trabajo de la mujer, sobre todo en los inicios de una obra. Sin embargo, el problema se presenta cuando la obra pentecostal se traslada de la casa-templo al templo-casa, donde la mujer es relegada y pierde protagonismo.

[...] A nuestra hermana Juanita Crisosto de Inzunza [...] Le correspondió, pues, la dura tarea de predicar el evangelio junto su esposo, pero la tarea recayó principalmente en nuestra hermana Juanita, ya que su esposo debía trabajar en lo material para el sostén de la familia. Se le vio entonces, a ella con sus pequeños hijos, realizando la labor evangelista por las calles de la ciudad, visitando enfermos, socorriendo al necesitado, compartiendo con sacrificio el sustento de su hogar [...] a comienzos del año 1964, el pastor Inzunza fue designado para suceder al pastor, Daniel Vega, en la Iglesia de Concepción y la hermana a tuvo que ir con su esposo [...] a esto se le sumó, que deseando

55 Ricardo Foulkes, «Conflictos en Corinto: las mujeres en una iglesia primitiva», RIBLA (1993): 107-122.

56 Revista Fuego de Pentecostés, n. 650 (noviembre de 1983): 16. 57 Pertuz, «Carta a Filemón». 
que la viuda del Pastor Venegas continuara ocupando hasta su muerte la casa pastoral existente, debieron vivir en casas arrendadas los tres primeros años $[\ldots]^{58}$.

Se resalta la mujer como pionera, fundadora de iglesias pentecostales y predicadoras de la calle. Ella se hace predicadora sin abandonar sus roles maternales y domésticos que también son considerados de manera significativa: ser esposa y madre, por ello sale a predicar a la calle con sus hijos. Otro aspecto relevante que se destaca en esta esquela mortuoria es la falta de reconocimiento de la mujer respecto al derecho sobre la residencia del pastor. Así, la casa pastoral es el hogar de la familia en tanto vive el pastor, si este muere la mujer pierde el derecho a ocupar la vivienda-templo que ambos han construido, puesto que esta es propiedad de la comunidad, quedando la mujer junto a su familia abandonada por la propia congregación. Este abandono se expresa además en términos de ayuda económica: no llegan los diezmos, primicias u ofrendas de la iglesia, por lo que vive de la ayuda brindada por la familia o por la solidaridad de algunos hermanos. Hemos escuchado relatos de pastoras que mueren en la soledad y en la pobreza. Como dice Pertuz, se necesita recuperar la memoria del sufrimiento y de la exclusión de las mujeres. Eso posibilita la solidaridad universal entre las mujeres del pasado, del presente y del futuro $^{59}$. La actividad de ella no solo aparece relegada al varón, sino que también sometida y relegada frente al protagonismo masculino.

[...] A veces por mi trabajo no alcanzaba a llegar a tiempo al punto de predicación y ella dirigía el trabajo, los hermanos que mucho la respetaban y la amaban [...] formó una clase hermosa Clases de Dorcas y con ellas trabajaba predicando los viernes, visitando hogares y enfermos [...] atendió, siempre, la hermandad como una madre, el comedor lleno de hermanos y siempre sirviéndoles con una sonrisa a flor de labios $[\ldots]^{60}$.

Se resalta en la pastora su asistencia frecuentemente a los puntos de predicación ${ }^{61}$, haciéndolo en la

58 Revista Fuego de Pentecostés, n. 677 (enero de 1986): 14. 59 Pertuz, «Carta a Filemón».

60 Revista Fuego de Pentecostés, n. 710 (octubre de 1988): 16.

61 Los puntos de predicación es el términos pentecostal para decir los lugares que ellos cartografiaban moralmente antes de ir a predicar, que generalmente tenía que ver con lugares como los bares, prostíbulos o canchas de fútbol. calle y dirigiendo la predicación. Vuelve a destacar el carácter doméstico y la extensión maternal de la pastora: alberga a los desamparados, les da de comer y visita a los necesitados, quienes la maternalizan y la ven como madre espiritual. La esposa del pastor se describe como co-pastora predicando y asumiendo responsabilidades con su esposo, resaltando su actividad protectora y maternal. Además, durante la década de 1980, en el país se organizaban las denominadas ollas comunes, de las cuales no participaban los pentecostales. La congregación realizaba sus propios comedores en los templos o en las casas de los pastores, siendo la mujer la encargada de implementar esta actividad.

Biografía de nuestra Amada Hermana Elisa Cuevas de Pino (Q.E.P.D). Elisa Cuevas Graniffo nació en Santiago el 15 de septiembre de 1928. Ella tuvo la dicha de «nacer en cuna del evangelio» [...] fue una sierva de Dios, fue notoria en todo tiempo su grata hospitalidad, «su casa era el hogar de todos los hermanos». Pero también muchas veces del necesitado y desamparado, a los cuales el Señor nos llama a amar y auxiliar en sus necesidades materiales y espirituales [...] El Señor miró su jardín y tomó esta hermosa azucena, para hacerla reposar en su amoroso pecho por la eternidad ${ }^{62}$.

La pastora es vista como sierva de Dios: hospitalaria y comensal, predicadora de la Palabra en la calle, en el barrio, en el hogar. Una vez más la pastora y las mujeres son las encargadas de atender a la comunidad. El hogar, en este sentido, es morada familiar y comunitaria, espacio de responsabilidad femenina ${ }^{63}$.

\section{Predicadora}

Navia destaca que la situación de la mujer en los barrios populares latinoamericanos resulta ambivalente: de un lado, se observa una situación de dependencia del hombre y opresión en una cultura patriarcal; de otro lado, es una situación de una gran potencialidad creadora: sostiene la familia, educa, saca proyectos adelante, incide en la vida barrial ${ }^{64}$. Es una mujer que se socializa en las distintas instituciones para ser rescatada por

\footnotetext{
62 Revista Fuego de Pentecostés, n. 738 (febrero de 1991): 19.

63 Elaine Neuenfeldt, «iMujeres con fuerza y poder!», RIBLA, n. 51 (2006). http://www.claiweb.org/ribla/ribla51/mujeres\%20con\%20 fuerza.html (consultado el 16 de marzo de 2014). 64 Navia, «La mujer en la Biblia».
} 
el hombre, pero también es una mujer que busca redimir a otros a través de la palabra.

La Hermana María Rogelia Vda. de Pastor de Barrera, creyó en el Señor Jesucristo en el año 1935, en el pueblo de la Florida [...] desde entonces comenzó a servir al Señor con mucha gratitud, no importándole lo que le significaba caminar 14 kilómetros de ida y vuelta a casa, pero estaba en todos los servicios, ya sea de predicaciones o reuniones. Su esposo, también un buen cristiano, pasaba más tiempo enfermo que sano; ella afrontó la vida como una esposa ejemplar y madre abnegada luchando por sus hijos [...] su casa era la casa de todos sus hermanos de la iglesia; cuando iban a predicar a la Florida, su mensaje estaba siempre puesta para los siervos del Señor, atendiéndolo con lo mejor que tenía $[\ldots]^{65}$.

La mujer pentecostal es una predicadora en la calle. Frente a la ausencia del esposo-pastor se destaca como esposa ejemplar y madre abnegada, asumiendo además el rol de proveedora del hogar. Está frente a un constante desafío al concebirse la casa pastoral como extensión del templo, por lo cual la esposa del pastor, aparte de predicadora, sigue siendo hospitalaria y acogedora, ampliando su rol respecto a la familia; más que pastora es concebida como madre espiritual. El pentecostalismo sin el rol de las mujeres predicadoras y de las pastoras no sería más que un címbalo que retiñe añejas melodías sin sentido para América Latina. Precisamente no hay pastores sin pastoras, y no por el rol doméstico de ellas, sino por su rol público, invisibilizado y negado.

Biografía de Nuestra Amada Hermana María Bravo Vda. de Zúñiga (Q.E.P.D) [...] Desde un principio abrazó de lleno el evangelio, a cuya predicación se dedicó con gran esmero, no escatimando su vida en este glorioso trabajo, ni las distancias fueron motivos para detenerla. Caminaba desde León Prado hasta Buzeta, llevando a aquellas almas sedientas la preciosa semilla del evangelio [...] junto a su esposo inicia distintas tareas, llena de virtuosidad con que Dios adorna a la mujer cristiana supo ser la ayuda idónea, la compañera leal y abnegada $[\ldots]^{66}$.

La pastora es representada como una esmerada predicadora a costo de caminar largas distancias y se resaltan las metáforas campesinas, porque lleva la semilla y el agua a las almas sedientas.

65 Revista Fuego de Pentecostés, n. 682 (junio de 1986), 12-13. 66 Revista Fuego de Pentecostés, n. 746 (octubre de 1991): 19.
Nuestra Amada Hermana Laurita Soto Coronado [...] al convertirse al Señor, se propuso orar y predicar su santo evangelio a sus padres y un tío, objetivo que se cumplió, pues el Señor salvó a sus padres y a su tío, ganándolo para Dios [...] Dios la usó para predicar junto a su madre por los campos, levando la semilla del evangelio [...] por el año 1952 comienza a sentir el llamado de parte de Dios a su santo; por hallar muy grande esta responsabilidad, hasta que un día tiene una revelación [...] quien le dice: «Laurita, Laurita, ¿hasta cuándo te resiste? Sal de tu tierra y de tu parentela a la tierra que yo te mostraré», al vivir ella esta experiencia, dice a su esposo: $« \mathrm{Si}$ hemos de salir mañana, vámonos hoy y obedezcamos al Señor, arréglame cajas y maletas para llevar nuestros enseres» y así obedecieron al Señor $[\ldots]^{67}$.

La pastora es contemplada como una mujer de oración y de predicación: predica a su familia hasta lograr la conversión de todo su grupo familiar, para luego predicar junto a ella en la comunidad. La metáfora de la campesina surge con fuerza, la mujer esparce la semilla del evangelio de manera itinerante, por pueblos y campos. Frente al llamado pastoral de su esposo, la voz y la decisión de la mujer como pastora, compañera, colaboradora y ayudante es fundamental, porque no hay pastor sin pastora.

\section{Madre}

En sociedades desiguales y con altos índices de pobreza, la figura de la mujer madre es central para la sobrevivencia. En Chile se observa una alta mortalidad infantil hasta la segunda mitad del siglo xx, con una esperanza de vida muy baja. En este contexto la labor de la madre consiste en garantizar la vida de los hijos. Como señala Navia, para todos los pueblos la maternidad está ligada a la vida. La vida como futuro, como apertura, como posibilidad plena, y la mujer está en el centro de esa vida ${ }^{68}$.

Nuestra Amada Hermana Flora Rivera de Sánchez [...] la hermana Florita no pierde tiempo, empieza a realizar las labores de esposa de Pastor, sin dejar de ser madre de ocho hijos, y trabajando tenazmente se gana el respeto y cariño de las almas humildes de nuestros campos. Su casa es la casa de sus hermanos, su mesa recibe a todos con el mismo cariño y en ella siempre está la palabra de cariño, estímulo y aliento, sabe llorar con el que llora y comparte también las alegrías de su her-

67 Revista Fuego de Pentecostés, n. 865 (septiembre de 2001): 2. 68 Navia, «La mujer en la Biblia». 
mandad sobrellevando sus propias enfermedades [...] sabiendo que al final de la carrera está el premio $[\ldots]^{69}$.

La exaltación de la esposa de pastor se realiza en función de la maternidad y su reciprocidad con la acción religiosa con la comunidad. La casa pastoral como extensión del templo, como«la casa pastoral es la casa de los hermanos» y «la mesa pastoral es la mesa de los hermanos». No hay distancia entre la casa y el templo, sino que se corresponde la función familiar con la comunitaria, en tanto que el desempeño del rol femenino está altamente definido y acotado.

[...] nuestras hermanas Carlota Vidal de Gutiérrez [...] Desde sus primeros días Dios la honró con cargos de importancia los cuales supo cumplir. No fueron impedimento sus diez hijos que crió; muchas veces llevando en sus brazos a alguno de ellos a la oración de la mañana, la predicación o a los campos [...] aunque quebrantada, a veces en su salud, nunca dejó la oración de la mañana, la atención de la hermandad, y de los menesterosos que acudían cada día a buscar su alimento a la puerta de la casa pastoral $[\ldots]^{70}$.

El gran tamaño de la familia está presente en estas citas. Una abundante descendencia es una bendición para la familia y una responsabilidad para la mujer, además son recursos para el pueblo en momentos históricos en los que las amenazas de pobreza y hambre se enfrentan garantizando la mano de obra. En los dominios de la cultura patriarcal la mujer es despojada de bienes económicos, de reconocimiento social y derechos políticos, los hijos se convierten en su único patrimonio, constituyen la posibilidad de una reivindicación y por tanto son para sí. Desde aquí se les educa ${ }^{71}$. La Pastora es madre de una familia numerosa, con tiempo para dedicarse a la ritualidad de la oración y a la predicación callejera en el campo y pequeños pueblos.

Biografía de Nuestra Amada Hermana Delfina Cortés de Lemus (Q.E.P.D) [...] mi esposa era verdaderamente una ayuda idónea. Jamás me reprochó por el exceso de trabajo que Dios nos daba, todo lo contrario, se apuraba, dejaba la casa muy bien organizada, ya teníamos once hijos, y sin por algún motivo me atrasaba, ella estaba en las dorcas, visitando enfer-

69 Revista Fuego de Pentecostés, n. ${ }^{\circ} 857$ (enero de 2001): 2. 70 Revista Fuego de Pentecostés, n. 795 (noviembre de 1995): 2.

71 Navia, «La mujer en la Biblia». mos, en la predicación de la calle...en nuestra casa las visitas siempre abundaban, llegaban a orar, cantar y se manifestaba el Señor. A todos los que venían los atendía con mucho cariño, pasaba susto el cilindro de gas, duraba poco, pero cuando se acababa, ella lo ungía en el nombre del Señor, y seguía saliendo gas, eso sucedió muchas veces, hasta que teníamos dinero para comprar el gas $[\ldots]^{72}$.

Se elogia la pastora como madre, se ensalza como colaboradora del esposo, como mujer silente, su casa está abierta, dispuesta para la gran familia de la congregación, su trabajo (doméstico-extendido a la comunidad) manifiesta la dimensión de madre material y espiritual.

\section{Visitadoras sociales}

Un aspecto bastante significativo y reiterativo es la pastora como visitadora social dedicada a la atención de enfermos y necesitados.

Biografía de Nuestra Hermana Misionera Rita Marta Sánchez Araya [...] el trabajo era diario, visitando los hospitales y en las cárceles a aquellos hombres que nadie visitaba. Los traían los gendarmes descalzos desde sus celdas, sin camisas. Allí aportaban todo lo material y luego le hablaban del Señor. Muchos salieron cambiados por el poder de Dios. También visitaban a los que iban quedando en el camino [...] su trabajo solo se terminó cuando sus ojos se cerraron, ya que debido a su enfermedad no podía salir. Sin embargo siguió trabajando desde su lecho, por teléfono y por las innumerables hermanas que le visitaban $[\ldots]^{73}$.

La pastora es una visitadora social que se preocupa de los hospitales y cárceles, los encarcelados y los enfermos, los más necesitados de compañía y cuidados.

A la pastora se le representa con otros símbolos: una metáfora arquitectónica concebida como una columna, es decir una pieza arquitectónica vertical y de forma alargada que tiene como función sostener el peso de la estructura social y que además cumple funciones estéticas. Es metáfora arbórea al representar la pastora como un árbol plantado junto a un arroyo, siempre activa y dispuesta. También es la metáfora agrícola al representarla como una agricultora que pone las manos en la mancera del arado para sembrar y

72 Revista Fuego de Pentecostés, n. 819 (noviembre de 1997): 23

Las pastoras pentecostales: metáforas sobre el liderazgo femenino / Miguel Ángel Mansilla Agüero, Luis Orellana / 95 
trabajar sin mirar atrás. Además, es la metáfora del faro en cuanto a la idea de una torre iluminada situada cerca de la costa o situada dentro del mar a cierta distancia de la costa, que se ubica en los lugares donde transcurren las rutas de navegación de los barcos y la utilizan como guía y luz para la congregación, especialmente para aquellos que viven momentos difíciles como los encarcelados, los enfermos y desempleados.

\section{Conclusiones}

En los relatos pentecostales está el reconocimiento al trabajo de la pastora de forma contradictoria y ambigua.

Las metáforas referidas a la pastora se construyen desde una dimensión femenina-materna dependiente del protagonismo-masculino del esposo-pastor. De esta manera, la reiteración de la imagen de la mujer, a partir de las metáforas construidas por la congregación, permiten, como dice Bourdieu, la transmisión y asimilación del sexismo y de la sumisión de la mujer en el pentecostalismo, construcción social que fomenta la permanencia de la dominación masculina ${ }^{74}$. En este sentido se ha continuado con el anacronismo de que «detrás de un gran pastor hay una gran pastora», el cual se corresponde con una religión que reproduce y fomenta acusadas diferencias de género asentadas sobre una concepción patriarcal. Allí prevalece la dualidad entre el predominio masculino y el sometimiento femenino. Esto conlleva a que la acción destacada de las pastoras dentro del pentecostalismo no reciba un suficiente reconocimiento por parte de la congregación, la cual elogia las cualidades tradicionales de la mujer-madre, que se extienden al conjunto de la comunidad. Las mujeres no pueden acceder al púlpito del templo, aun cuando pueden predicar en la calle y en las casas-templos, y no pueden ser investidas de pastoras formalmente. Este discurso es sellado con la lápida mortuoria del liderazgo femenino: «que la mujer calle en la congregación».

74 Pierre Bourdieu, La dominación masculina (Barcelona: Anagrama, 2000).
Por otro lado, se destaca su ímpetu de precursora, liderazgo, habilidades predicativas y comunicativas y su hospitalidad, especialmente en el inicio del movimiento de la construcción del templo, aunque posteriormente es relegada a la función doméstica extendida. Para resaltar estos aspectos se imaginan distintas representaciones como: metáforas arquitectónicas, metáforas bélicas y castrenses, metáforas campesinas, metáforas agrícolas y metáforas ganaderas. Todas estas asignaciones hacia la pastora aluden al $\mathrm{pa}^{-}$ sado rural y campesino del movimiento pentecostal, las cuales responden, también, a su origen marginal. Estas metáforas manifiestan el carácter constructivo de la mujer, pero también igualitario con respecto al pastor. Resaltan su poder administrativo-eclesiástico, sus habilidades de predicadoras y su capacidad para generar y movilizar recursos para la construcción del templo, el crecimiento y la expansión de la congregación. Este discurso potencia la igualdad de liderazgo con la sentencia bíblica: «en Cristo, no hay hombres ni mujeres, porque todos son uno en Cristo». Sin embargo, la invención e interpretación de este segundo relato, referido a la pastora, solo se le reconoce una vez muerta, mientras que en vida solo es «la esposa del pastor», pero una vez muere era la pastora y la predicadora.

\section{Bibliografía}

\section{Fuentes primarias}

Revista Fuego de Pentecostés, n. 513 (1972). Revista Fuego de Pentecostés, n. ${ }^{\circ} 604$ (1979). Revista Fuego de Pentecostés, n. ${ }^{\circ} 625$ (1981). Revista Fuego de Pentecostés, n. ${ }^{\circ} 650$ (1983). Revista Fuego de Pentecostés, n. 677 (1986). Revista Fuego de Pentecostés, n. ${ }^{\circ} 682$ (1986). Revista Fuego de Pentecostés, n. 710 (1988). Revista Fuego de Pentecostés, n. ${ }^{\circ} 738$ (1991). Revista Fuego de Pentecostés, n. 746 (1991). Revista Fuego de Pentecostés, n. 795 (1995). Revista Fuego de Pentecostés, n. 819 (1997). Revista Fuego de Pentecostés, n. 827 (1998).

Revista Fuego de Pentecostés, n. 830 (octubre de 1998): 6.

Revista Fuego de Pentecostés, n. ${ }^{\circ} 857$ (2001). Revista Fuego de Pentecostés, n. 865 (2001). 


\section{Fuentes secundarias}

Andrade, Rosa. «Manos que sanan. Experiencia de salud en mujeres pentecostales chilenas». En Cultura y Religión 2, n. ${ }^{\circ} 3$ (2008). www.revistaculturayreligion.cl

Beauvoir, Simone. El segundo sexo. Madrid: Cátedra, 1998.

Betchel, Guy. Las cuatro mujeres de Dios: La puta, la bruja, la santa y la tonta. Madrid: Zeta. 2001.

Cardoso, Nancy. «Pautas para una hermenéutica feminista de la liberación». RIBLA,n. ${ }^{\circ} 25$ (1996): 5-10.

D’epinay, Cristian. El refugio de las masas: estudio sociológico del protestantismo chileno. Santiago: Pacífico, 1968.

Davis, Angela. 2004. Mujeres, Raza y Clases. Editorial. Akal, Madrid.

Dermeience, Alice. "Theologíe de la femme et theologie feministe». Revué Thelogique the Louvain, n. 31 (2000): 492- 523.

Foulkes, Ricardo. «Conflictos en Corinto: las mujeres en una iglesia primitiva». RIBLA (1993): 107-122.

Galilea, Carmen. El predicador pentecostal. Santiago: cisoc-Bellarmino, 1991.

Garma, Carlos. Buscando el espiritu. Pentecostalismo en Iztapalapa y la ciudad de México. México: UAM y Plaza Valdés, 2004.

Giddens, Anthony. Las nuevas reglas del método sociológico. Crítica positiva de los métodos comprensivos. Buenos Aires: Amorrortu, 1993.

Guevara, Ana. «Movimiento protestante en comunidades indígenas. Testimonio de vida y fe». En Cuarto Congreso Chileno de Antropología: sociedad moderna, globalización y diferencia. Valdivia, 2009.

Hurtado, Josefina. «Mujer pentecostal y vida cotidiana». En Huellas, Seminario Mujer y Antropologia, 73-86. Santiago: CEDEM, 1993.

Ibáñez, Fabiola. «Dios, la cabeza del hombre; el hombre, la cabeza de la mujer. Una aproximación a las relaciones de género en la iglesia evangélica pentecostal». Tesis de pregrado, Universidad Arturo Prat, 2003.

Jacobsen, Douglas. «María Beulah Woodworth-Etter (1844-1924). El lugar de una mujer está en el púlpito». En Enrichment Journal, 2009. http:// ag.org/enrichmentjournal_sp/200901/index.cfm.

Juárez, Elizabeth. "Las hijas de Eva. De la normatividad a la trasgresión». En Más allá del Espiritu, acciones y prácticas en iglesias pentecostales,
149-183. México: ciesas-Colegio de Michoacán, 2007.

Lindhardt, Martín. «Poder, género y cambio cultural en el pentecostalismo chileno». Cultura y Religión 3, n. ${ }^{\circ}$ 2, (2009): 94-112.

Löwy, Michael. Guerra de dioses: religión y política en América Latina. México: Siglo xxi, 1999.

Maduro, Otto. «Notas sobre pentecostalismo y poder entre inmigrantes latinoamericanos en la ciudad de Newark (New Jersey, E.U.A.)». Horizonte Antropológico 13, n.o 27 (2007): 13-35.

Mansilla, Miguel. «Irán andando y llorando llevando la semilla... Las imágenes de los pastores pentecostales a través de la muerte y la memoria 1909-1950». Revista Pandora, n. 25 (diciembre de 2010). http://revistapandorabrasil.com/revista_pandora/religiao/texto_5.pdf.

Mansilla, Miguel. «Nacidos en la calle: De la construcción bestial del predicador callejero a su construcción como patrimonio cultural». Revista Si Somos Americanos 7, n.o 1 (2006): 112-145.

Martín, David. «Otro tipo de revolución cultural: El protestantismo radical en América Latina». Revista de Estudios Públicos, n. ${ }^{\circ} 44$ (1991): 39-62.

McGee, Gary. «Alice Eveline Luce». En Biographical Dictionary of Christian missions, editado por Gerald H. Anderson, 414. Nueva York: Macmillan, 1999.

Méndez-Peñate, Adriana. «Una espiritualidad para la mujer». RIBLA, n. ${ }^{\circ} 13$ (2000): 87- 103.

Mendoza, Rosa. «Pentecostalismo popular en Akil, Yucatán». Revista Mexicana del Caribe viı, n. ${ }^{\circ} 14$ (2002): 105-144.

Montecino, Sonia. «Caminar con el espíritu: perspectivas de género en el Movimiento Evangélico Pentecostal». Centro de Estudios Públicos, no. 87 (2002): 73-103.

Moya, Marcia y Helmut Renard. «La mujer que sin nombre y sin hombre se salva a sí misma. 'Mujer, tu fe te ha salvado'». RIBLA, n. ${ }^{\circ} 49$ (2004): 46-57.

Navia, Carmiña. «La mujer en la Biblia: opresión y liberación». RIBLA, n. 9 (1991): 57-79

Neuenfeldt, Elaine. «iMujeres con fuerza y poder!». RIBLA, n. 51 (2006). http://www.claiweb.org/ribla/ribla51/mujeres\%20con\%20fuerza.html

Orellana, Luis. El fuego y la nieve: Historia del movimiento pentecostal de Chile 1909-1932. Concepción: Ceep ediciones, 2008. 
Orellana, Zicri. «La Iglesia Pentecostal: comunidad de mujeres». Cultura y Religión 3, n. ${ }^{\circ} 2$ (2009): 119-132.

Orellana, Zicri. Mujeres pentecostales: Construcción del género a través de la experiencia religiosa. Chile: Aire Libre, 2010.

Ossa, Manuel. Espiritualidad popular y acción política. El pastor Victor Mora y la Misión Wesleyana Nacional. 40 años de historia religiosa y social (1928-1969). Santiago: Rehue, 1990.

Palma, Irma. En tierra extraña. Itinerario del pueblo pentecostal chileno. Santiago: Amerindia, 1988.

Pentecostal Iglesia del Evangelio Cuadroangular. 1923-2014. http://www.foursquare.org/landing_pages/8,3.html

Pertuz, Maribel. «Carta a Filemón desde la perspectiva feminista». RIBLA, n. ${ }^{\circ} 28$ (1997): 37-43.

Pierre, Bourdieu. La dominación masculina. Barcelona: Anagrama, 2000.

Rivera, Carolina. «La comunidad eclesial y la comunidad moral: ¿dos realidades en sintonía?». En Más allá del espiritu. Actores, acciones y prácticas en Iglesias Pentecostales, 117-147. México: ciesas y E1 Colegio de Michocán, 2007.

Scattered Christians. 2014. http://scatteredchristians.org/PentecostalWomen.html.

Sepúlveda, Juan. De peregrinos a ciudadanos. Breve historia del cristianismo evangélico en Chile. Santaigo: Fundación Konrad Adenauer; fET y CTE, 1999.

Slootweg, Hanneke. Mujeres pentecostales en Chile: un caso en Iquique. Chile: TER, 1989.

Tamez, Elsa. «Pautas hermenéuticas para comprender Ga. 3,28 y 1 Co. $14,34 »$. RIBLA n. ${ }^{\circ} 15$ (1992), 9-18.
Tarducci, Mónica. «Estudios feministas de religión: una mirada muy parcial». Cuadernos Pagu Universidad de Campinas, n. 16 (2001): 97-114.

Tarducci, Mónica. «Estudios feministas de religión: una mirada muy parcial». Cuadernos Pagu Universidad de Campinas, n. ${ }^{\circ} 16$ (2001): 97-114.

Tarducci, Mónica. «Solo respondo al llamado de Dios. E1 precario liderazgo de las pastoras pentecostales». AIBR. Revista de Antropología Iberoamericana, n. ${ }^{\circ} 40$ (2005): 1-21.

Tennekes, Hans. El movimiento pentecostal en la sociedad chilena. Ámsterdam: Ciren y Facultad de Antropología Cultural y Sociología No Occidental. Universidad Libre de Ámsterdam-CIREN, 1985.

Wurmbrand, Richard. Torturado por Cristo: La iglesia mártir de hoy. Londres: Hayfield $\mathrm{Pu}-$ blishing co., 1979.

Zaballo, Virgilio. Una nube de testigos. Un compendio de la historia del cristianismo a través de muchos de sus protagonistas. Inglaterra: Fundación DCI, 2007. http://www.scribd.com/doc/23193074/Vi rgilio-Zaballos-Una-nube-de-testigos

- Fecha de recepción: 4 de junio de 2013

- Fecha de evaluación: 20 de agosto de 2013

- Fecha de aprobación: 18 de septiembre de 2013

\section{Cómo citar este artículo}

Mansilla Agüero, Miguel Ángel y Luis Orellana. «Las pastoras pentecostales: metáforas sobre el liderazgo femenino en la Iglesia Evangélica Pentecostal (1972-2001)». Memoria y sociedad 18, n. ${ }^{\circ}$ 36 (2014): 83-98. http://dx.doi.org/10.11144/Javeriana.MYS18-36.ppml 